\title{
Evolution of Concepts in Forest Pathology
}

\author{
Paul D. Manion
}

State University of New York, College of Environmental Science and Forestry, Syracuse 13210. Accepted for publication 7 March 2003.

\begin{abstract}
Manion, P. D. 2003. Evolution of concepts in forest pathology. Phytopathology 93:1052-1055.

Foundation concepts in forest pathology are based on experiences evolving over time. Three examples will be addressed. (i) The primary concept behind education and research in forest pathology is the widely accepted attitude that disease-causing agents limit full utilization of forest resources. Therefore, we study diseases to find a weak link and then utilize this information to enhance our portion of the shared resource. The sustainable environmental issues of today have changed this

concept, in my mind, to one of addressing what is the appropriate "healthy amount of disease" in a sustainable forest ecosystem. (ii) The initial concept that weakened understory trees and poorly managed forests deteriorate and decline over time because of numerous insults from biotic and abiotic agents has evolved into a decline disease stabilizing selection concept whereby healthy dominant trees in the forest (the survivors) are selectively killed by a combination of specifically ordered factors. (iii) The concept that heart-rot decay is initiated by infection through wounds that expose heartwood has evolved into the concept of infection in the sapwood that is compartmentalized over time in the center of the tree.
\end{abstract}

In the latter part of the 19th century, Robert Hartig established the foundation for concepts in forest pathology (11). His concepts were based on the recently evolved germ theory that has been the cornerstone for modern medicine, plant pathology, and forest pathology, as well as an array of industrial processes today. Although the core concepts of our profession trace their origins to these earlier points in time, much of the rest of the foundational concepts for forest pathology are still in a dynamic evolutionary flux. Experiences over time provide the basis for new concepts that may seem contrary to traditionally accepted ideas. Looking to the future, one must assume new experiences will modify our current concepts. A book like "Tree Disease Concepts" (7) may seem like a definitive compilation of concepts for students, but unfortunately, or possibly fortunately, both the author and the readers need to adjust their interpretation of what is written as concepts continue to evolve over time.

This symposium attempts to highlight the past as well as the future for forest pathology. My specific objective is to highlight three examples of evolutionary changes in fundamental concepts of forest pathology that have significantly altered my way of thinking and consequently my teaching. The initial concepts were that (i) diseases represent an unhealthy condition, (ii) tree decline is a problem of weakened unfit trees, and (iii) heart rot is decay of dead heartwood. This paper summarizes how these earlier concepts have evolved to the understanding that (i) forests need a healthy amount of disease, (ii) decline diseases kill the biggest and best trees to stabilize the forest, and (iii) heart-rot decay is initiated in the sapwood and compartmentalized to the center of the tree.

Forests need a healthy amount of disease. As plant pathologists, we all learn very early that disease represents an unhealthy condition. Furthermore, this negative connotation for disease was

Corresponding author: P. D. Manion; E-mail address: pdmanion@esf.edu

Publication no. P-2003-0602-060

(C) 2003 The American Phytopathological Society nurtured from early childhood. Therefore, the evolution of "diseases as the unhealthy condition" to "forests need a healthy amount of disease" may be difficult to accept. This transformation of diseases as negative factors into positive factors involves the appropriate characterization of a role for diseases in the forest and the development of a quantitative baseline for assessing impacts above or below the predicted baseline.

Current interest in documenting the health of the forest has fostered a need to better understand the role of diseases in forest health. Spatial and quantitative characterization of diseases and pests has been the traditional approach to forest health monitoring and reporting. Does anyone know how to interpret a map with different colors or shading representing damage area in percent total forest area? These types of charts come and go, but in most instances the forest remains. The real questions are not where and how much. The questions should be where is there an impact and what is the magnitude of the impact? It is possible and highly probable that presence of disease-causing agents does not necessarily relate directly to some type of negative impact.

If presence does not necessarily relate directly to negative impact, then maybe there are other roles for diseases in the forest. Yes, a number of papers have summarized specific positive roles for diseases in the forest (literature citation 1 provides an example). But, these papers do not provide an overall general framework for considering the relationships of both positive and negative impacts of diseases in the forest system. The Phoenix helix (Fig. 1) visualization of the forest system attempts to provide an overall framework for considering the relationships of diseases in the forest system (8). The metaphor relates decreasing density with size in an inward and upward time spiral. Forests, like the legendary bird, therefore sustain life from death, but unlike the one-for-one replacement in the legendary bird, the forest sustains life for the system from systematic death of portions of the system over time. What facilitates the reductions in numbers of individual trees as they grow over time? Figure 1 characterizes disease-causing agents as regulators, terminators, and resource recovery agents, the factors contributing to the death of large 
numbers of trees (the forest behind the trees). The forest is therefore sustained over time by a "healthy amount of disease." Disease-causing agents in this instance are defined in a very broad sense to include any agent that may negatively impact the survival of an individual tree.

The forest health question is not where and what amount of a pathogen or pest, but rather where does the combined impact of all pathogens and pests exceed a level that is appropriate for the sustainability of the system and what is the magnitude of the excess impact? Sustainability is often subjectively described, but sustainability can be objectively quantified by comparing actual mortality (observed percentage of dead trees) in relation to a predicted baseline mortality (predicted percentage of dead trees) to sustain the current forest system (8).

Baseline mortality is characterized as the amount of mortality required to indefinitely maintain the current forest structure. Baseline mortality (Fig. 2, dashed line) is calculated from the slope of the best-fit regression line (Fig. 2, solid line) for the natural logarithm of observed tree densities (Fig. 2, triangles) across diameter classes using the expression $m=1-e^{a X}$, where $m$ is baseline mortality (the predicted dead fraction), $e$ is the natural logarithm, $a$ is the slope of the best-fit regression line of the natural logarithm of density by diameter class, and $X$ is the diameter size class interval. Baseline mortality (dashed line), observed total mortality (filled circles), and cut trees (open circles) are plotted as percentages of all trees in each diameter class. All dead trees that have sufficient structure to be measured and have sufficient bark for identification purposes are included in the observed mortality.

Baseline mortality is the healthy amount of disease of the system required to maintain the current density by diameter distribution as populations of trees grow from one diameter class into another. In New York State, baseline mortality in forests and for the major tree species is generally around $20 \%$ per $2.5-\mathrm{cm}$ - diam- eter class. A healthy amount of disease would lead to death of approximately one in five trees for each $2.5 \mathrm{~cm}$ of growth. Sugar maple in northern New York State has an array of disease-causing agents, but overall mortality in the lower diameter classes is less than baseline (Fig. 2). Cutting in medium to larger diameter classes when combined with natural mortality generates a total mortality greater than baseline. Sugar maple in this northern New York sample is therefore not a sustainable healthy population based on current cutting and natural mortality.

Baseline analysis of the healthy or unhealthy amount of disease is applicable for a large forest system. Synchronizing events associated with individual stands may alter the density by diameter relationship. Groups of stands combine together into a sustainable system. The sugar maple population discussed previously is based on 1,236 trees from 279 randomly located sample plots from the forest region of northern New York State (9).

The evolution of disease as an unhealthy condition to the forests need for a healthy amount of disease provides a foundation concept that should reduce the misuse of confusing, often inflammatory, anecdotal and subjective characterization of diseases of the forest. What is needed is proper quantification of those situations in which diseases and other events combine to impact the sustainability of forest systems. The healthy amount of disease concept, based on the Phoenix helix metaphor and baseline mortality assessment procedures, is suggested as a framework for others to consider.

Decline disease kills the biggest and best trees to stabilize the forest. Widespread mortality in eastern Canada and northeastern United States of birch, maple, ash, oak, and other tree species in the 1960s stimulated a number of forest pathology groups to use the fundamental germ theory concept of our profession to find the causal factors. Inability to find a single pathogen lead to the multiple factors (predisposing, inciting, and contributing factors) decline concept, first proposed by Sinclair (16). This concept was

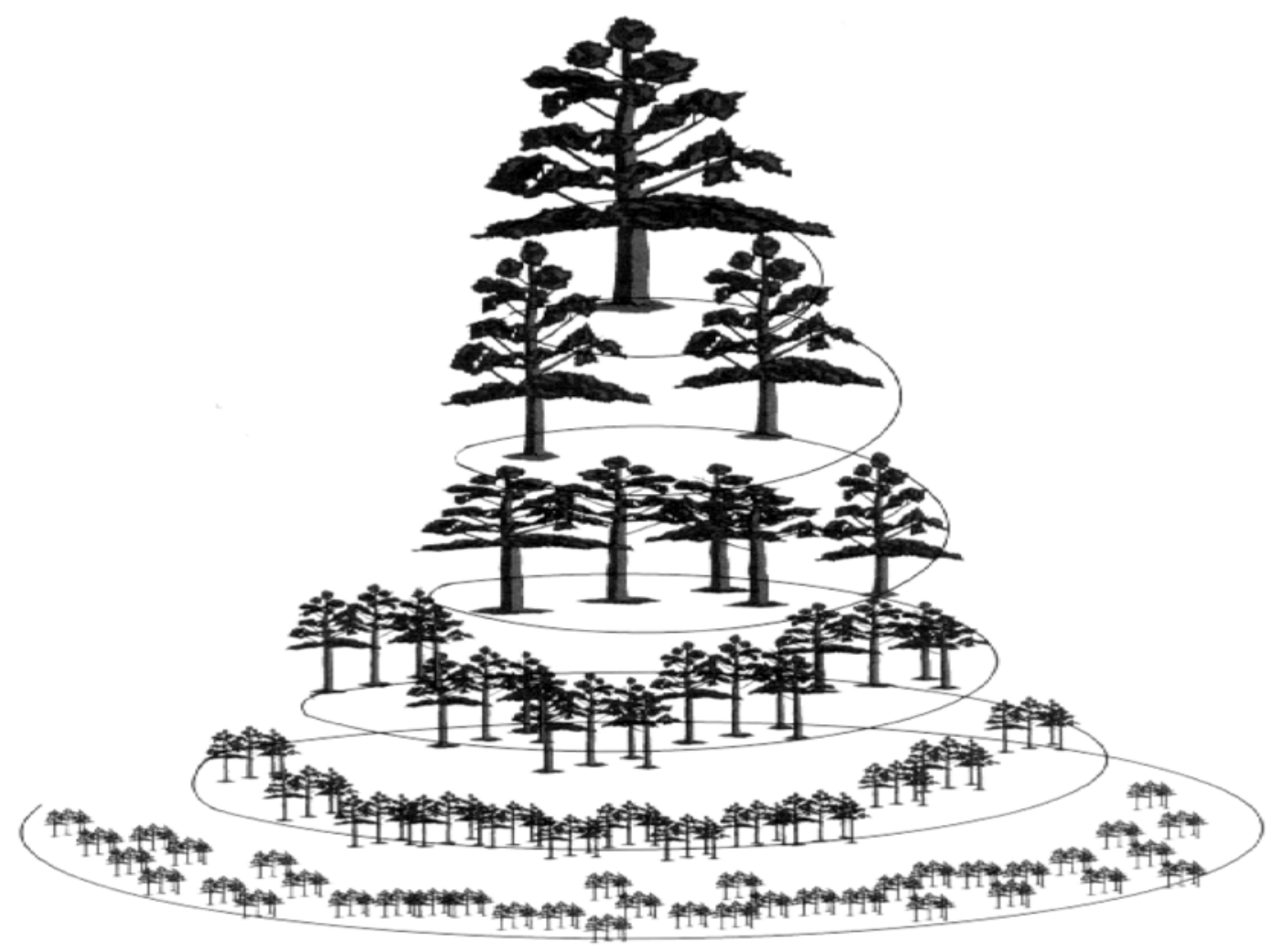

Fig. 1. Phoenix helix characterization of a forest system relating density to size class. The forest system, like the mythical bird, sustains itself based on a capacity to derive life from death, not in a one-for-one replacement, but rather based on systematic death of portions of the system to allow for growth and sustainability of the total system. Regulators, terminators, and resource recovery agents contribute to a "healthy amount of disease" in the forest behind the trees. 
later expanded to include other complex diseases and illustrated as the decline disease spiral diagram (7). Multiple step equation-like diagrams have also been used to characterize these complex diseases (6). These and other aspects of forest decline were reviewed and summarized in the book entitled "Forest Decline Concepts" (10).

Many have used these and other similar concepts to interpret an array of tree dieback situations. It is hard to document the origins and specific examples, but there is a general interpretation of the decline disease concept as describing the process for removing weakened, less fit trees from the population (literature citation 3 provides an example). The decline disease concept evolved to explain the death of seemingly fit trees of the population. Death of canopy dominant (12) mature trees is not a process of removing weakened, less fit individuals. Canopy dominant mature trees are the winners in the fitness selection process. Consider the numbers of less fit individuals that were removed using the Phoenix helix concept discussed previously. Decline diseases are a means for killing the biggest and best trees in the forest system.

A possible explanation and interpretation for the death of the biggest and best can be derived from two general ecological concepts (10). One concept categorizes life strategies for species of plants into competitive dominants and stress-tolerant dominants (4). Different individuals within a species can also be characterized as having competitive dominant or stress-tolerant dominant tendencies. Competitive dominance is often the selection criterion used in tree improvement programs.

The second ecological concept is the zero-force relationship (13), which simply suggests that ecological stability over time is dependent on no change. This seemingly circular argument is the foundation for looking at what leads to change and what leads to stability.
Consider, for example, a population of trees that has $20 \%$ baseline mortality for each $2.5 \mathrm{~cm}$ of growth. The less-fit individuals are culled from the population over and over again such that the large mature canopy dominant individuals represent a narrower range of "improved" genetic potential than the original population. The canopy dominant trees are the best competitive dominants of the original population when the environmental conditions are relatively constant. If the breeding population for future generations was limited to the competitive dominant "improved" population, this would not lead to stability characterized by a zero-force relationship because the population would become "bigger and better" with each generation. Zero force could be achieved in this predisposed population if a decline disease, incited or triggered by an unusual short-term alteration in the environment, tipped the balance occasionally against the competitive dominants to allow stress-tolerant dominants to attain canopy and breeding positions in the population.

The mechanism involved in the death of the most-fit individuals of the population relates to the competitive dominant versus stress-tolerant dominant strategies. Competitive dominant trees mobilize resources to build a large crown and a large root system. They also have a long, high-volume transport system to tie the top and bottom together. They maintain their competitive advantage by stretching the length and flow rate limits of the transport system to balance the large crown and large root mass. Because most of the transport in a tree occurs in the most recent annual ring, a large annual growth ring must be produced each year. An unusual disturbance (inciting factor) affecting either the top or the bottom of the competitive dominant (predisposed tree) will eventually be translated into a smaller annual ring. Restriction in transport capabilities will limit maintenance and recovery of the large crown, leading to physiological alterations that redirect limited

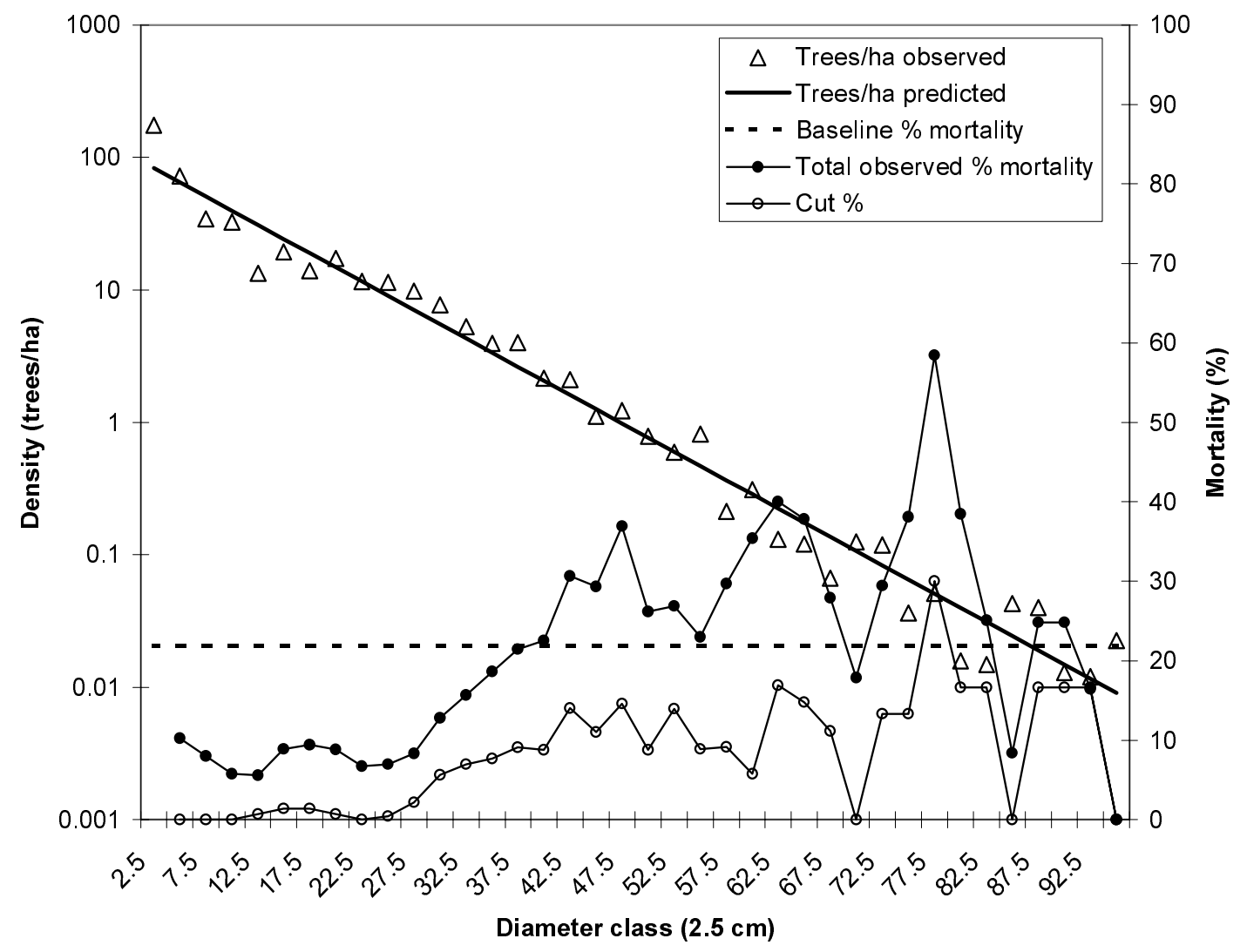

Fig. 2. Observed density, predicted density (least squares best-fit regression line), predicted percent baseline mortality (based on the slope of the regression line), total observed percent mortality, and percent cut trees across diameter classes of the sugar maple population of northern New York State. Total observed mortality exceeds the baseline mortality to sustain the population in the larger diameter classes. The data are based on 1,236 sugar maples from 612 random sample 10-basal-area-factor prism points in northern New York. Total observed percent mortality and percent cutting are expressed as three diameter class running averages to smooth out the line. 
resources into reproduction at the expense of growth. This reduced growth response further compounds the restriction of the vital transport system in subsequent years.

The cascade of events leading to decline and death of competitive dominant trees is less likely to occur in stress-tolerant trees that do not have large crowns and large root systems maintained by a high-volume transport system. Periodic inciting events and subsequent decline in canopy dominant trees provides an opportunity for the less competitive individuals to contribute to the gene pool for future generations. Decline diseases therefore contribute to the stability of the forest system.

Heart-rot decay fungi are compartmentalized. According to Merrill et al. (11), Hartig noted that the sapwood of Scots pine was fungus free and that the decay fungus Trametes pini (Phellinus pini (Thore:Fr.) A. Ames) utilized branch stubs to connect the interior fungus mycelium with the fruiting structure on the surface. He further reported that he could not infect 30- to 40-yearold Scots pines because of the lack of heartwood. This is the origin of the concept that heart rot was decay of heartwood and that infection occurred through exposed heartwood. Most forest pathologists accepted the heart rot of heartwood concept until recent decades when Shigo and Hillis (15) popularized their concepts of wood decay of trees based on years of cutting decayed trees, isolating fungi from decayed trees, and inoculating wounds in trees with decay fungi. Haddow (5) demonstrated a problem with Hartig's concept when he observed infection of small branches in white pine by $P$. pini. Etheridge and Craig (2) also emphasized the infection of small branches of western firs by Echinodontium tinctorium (Ellis \& Everh.) Ellis \& Everh. These earlier observations set the stage for a new concept on infection of sapwood and compartmentalization of decay in living trees. In simple terms, the compartmentalization concept provided a foundation for understanding the dynamic defenses of trees to infection. Trees utilize parenchyma cells in the sapwood to generate chemical and physical barriers to movement of hyphae of wooddecay fungi. These barriers plug cells above and below the wound. Parenchyma cells in the rays also generate a barrier to lateral expansion of the decay fungus. The chemical and structural differences between spring wood cells and summer wood cells of the tree slow down the interior invasion of the decay fungus. Cells laid down by the cambium shortly after the initial wound generate a ring of modified cells that act as a barrier zone to outward expansion of the decay fungus into xylem laid down in subsequent years (14). Future outward expansion of the decay column is ultimately dependent on another wounding event that breaks the barrier zone and/or the presence of a branch stub.

Heart-rot decay of living trees is much more than decay of dead heartwood. The compartmentalization concept provides a basis for understanding that infection and initial host responses of sapwood tissues in young trees are very important factors that influence decay patterns in older trees.

Summary and conclusions. The concept that "forests need a healthy amount of disease" provides a foundation for rational consideration of diseases in the forest. It leads to quantitative characterization of impacts on sustainability of the forest. The example of the sugar maple in northern New York illustrates a system that currently has an unhealthy amount of disease. This system theoretically would revert to a healthy sustainable system if cutting and natural mortality were maintained at or below baseline mortality.

The concept that "decline disease is a stabilizing factor in the forest" suggests a possible function for declines that should be considered when addressing the impacts of declines. The concept further suggests possible interactions of management activities that might set the stage for a decline. Activities that selectively enhance competitive dominant trees may generate increased economic return, but this activity might also lead to increased vulnerability to decline and death of this selected population of trees following short term inciting events.

The "compartmentalization" concept provides a framework for understanding the dynamic interaction of a decay fungus and a living host. Further understanding of the process should provide a basis for management activities in young trees to minimize heartrot decay impacts in older trees.

The three recently evolved concepts discussed previously are examples of the present vitality and dynamic state of forest pathology today. These modified concepts lead to an array of complementary as well as conflicting management implications for resource managers to consider. These and other concepts are not universally accepted, nor are they etched in stone for all times, but rather they provide a foundation for summarizing current discussion and thinking. Forest pathology will continue to build on its traditional as well as modified concepts.

\section{LITERATURE CITED}

1. Castello, J. D., Leopold, D. J., and Smallidge, P. J. 1995. Pathogens, patterns, and processes in forest ecosystems. BioScience 45:16-24.

2. Etheridge, D. E., and Craig, H. M. 1976. Factors influencing infection and initiation of decay by the Indian paint fungus (Echinodontium tinctorium) in western hemlock. Can. J. For. Res. 6:299-318.

3. Franklin, J. F., Shugart, H. H., and Harmon, M. E. 1987. Tree death as an ecological process. BioScience 37:550-556.

4. Grime, J. D. 1987. Dominant and subordinate components of plant communities: Implications for succession, stability, and diversity. Pages 413428 in: Colonization Succession and Stability, The 26th British Ecological Society Symposium. A. J. Gray, M. J. Crowley, and P. J. Edwards, eds. Blackwell Scientific Publications, Boston, MA.

5. Haddow, W. R. 1938. The disease caused by Trametes pini (Thore) Fries in white pine (Pinus strobus L.). R. Can. Inst. Trans. 47:21-80.

6. Houston, D. R. 1981. Stress triggered tree diseases-the diebacks and declines. U.S. Dep. Agric. For. Serv. NE-INF-41-81.

7. Manion, P. D. 1991. Tree Disease Concepts. 2nd ed. Prentice Hall, Englewood Cliffs, NJ.

8. Manion, P. D., and Griffin, D. H. 2001. Large landscape scale analysis of tree death in the Adirondack Park, New York. For. Sci. 47:542-549.

9. Manion, P. D., Griffin, D. H., and Rubin, B. D. 2001. Ice damage impacts on the health of forests in northern New York State. For. Chron. 77:619-625.

10. Manion, P. D., and Lachance, D. 1992. Forest Decline Concepts. The American Phytopathological Society, St. Paul, MN.

11. Merrill, W., Lambert, D. H., and Liese, W. 1975. Important Diseases of Forest Trees. Classics No. 12. The American Phytopathological Society, St. Paul, MN.

12. Muller-Dombois, D. 1992. A natural dieback theory, cohort senescence as an alternative to the decline disease theory. Pages 26-37 in: Forest Decline Concepts. P. D. Manion and D. Lachance, eds. The American Phytopathological Society, St. Paul, MN.

13. Pickett, S. T. A., and McDonnell, M. J. 1989. Changing perspectives in community dynamics: A theory of successional forces. Tree 4:241245.

14. Shigo, A. L. 1984. Compartmentalization: A conceptual framework for understanding how trees grow and defend themselves. Annu. Rev. Phytopathol. 22:189-214.

15. Shigo, A. L., and Hillis, W. E. 1973. Heartwood discolored wood and microorganisms in living trees. Annu. Rev. Phytopathol. 11:197-222.

16. Sinclair, W. A. 1965. Comparison of recent declines of white ash, oaks, and sugar maple in northeastern woodlands. Cornell Plantations 20: $62-67$. 